\title{
Congenital malaria in Urabá, Colombia
}

\author{
Juan G Piñeros-Jiménez ${ }^{1,2^{*}}$, Gonzalo Álvarez ${ }^{1}$, Alberto Tobón ${ }^{1}$, Margarita Arboleda ${ }^{3}$, Sonia Carrero ${ }^{1}$ and Silvia Blair ${ }^{1}$
}

\begin{abstract}
Background: Congenital malaria has been considered a rare event; however, recent reports have shown frequencies ranging from $3 \%$ to $54.2 \%$ among newborns of mothers who had suffered malaria during pregnancy. There are only a few references concerning the epidemiological impact of this entity in Latin-America and Colombia.

Objective: The aim of the study was to measure the prevalence of congenital malaria in an endemic Colombian region and to determine some of its characteristics.

Methods: A prospective, descriptive study was carried out in the mothers who suffered malaria during pregnancy and their newborns. Neonates were clinically evaluated at birth and screened for Plasmodium spp. infection by thick smear from the umbilical cord and peripheral blood, and followed-up weekly during the first 21 days of postnatal life through clinical examinations and thick smears.

Results: 116 newborns were included in the study and 80 umbilical cord samples were obtained. Five cases of congenital infection were identified (four caused by P. vivax and one by P. falciparum), two in umbilical cord blood and three in newborn peripheral blood. One case was diagnosed at birth and the others during follow-up.

Prevalence of congenital infection was $4.3 \%$. One of the infected newborns was severely ill, while the others were asymptomatic and apparently healthy. The mothers of the newborns with congenital malaria had been diagnosed with malaria in the last trimester of pregnancy or during delivery, and also presented placental infection.

Conclusions: Congenital malaria may be a frequent event in newborns of mothers who have suffered malaria during pregnancy in Colombia. An association was found between congenital malaria and the diagnosis of malaria in the mother during the last trimester of pregnancy or during delivery, and the presence of placental infection.
\end{abstract}

\section{Background}

Most neonatal and perinatal deaths are preventable. According to The State of the World's Children report, published in 2009, 3.7 million children die annually during the first 28 days of postnatal life, $75 \%$ during the first week and $36 \%$ due to severe infection [1]. Malaria continues to be one of the most important public health problems worldwide, and is responsible for $8 \%$ of the mortality among children below the age of five [1]. Plasmodium spp. is usually transmitted by Anopheles spp. mosquitoes, but can also be transmitted from mother to child causing congenital malaria $(\mathrm{CM})$ [2]. Maternal and placental infections caused by Plasmodium spp. are frequent entities in malaria endemic regions and have been extensively studied in Africa, Asia and Oceania; in contrast, there is little

\footnotetext{
* Correspondence: jgpinerosj@gmail.com

'Malaria Group, Universidad de Antioquia, Calle 62, \# 52-59, Laboratorio 610, Medellín, Colombia

Full list of author information is available at the end of the article
}

information regarding CM. The first studies by Covell and Bruce-Chwatt in the midst of the $20^{\text {th }}$ century reported an incidence of CM between $0.18 \%$ and $0.3 \%$ in newborns from mothers suffering from malaria during pregnancy in hyper-endemic regions $[3,4]$, and only 300 sporadic cases were reported worldwide in the literature during the next half century; therefore, $\mathrm{CM}$ has been considered a rare event [5]. However, since 1985 there have been reports of a CM incidence ranging from $4.9 \%$ to $54.2 \%$ in regions of Africa with stable malaria transmission, where it is more likely that the pregnant women have acquired immunity to prevent mother-to-child transmission [6-11]. The few reports in Latin America include some cases from Brazil, Mexico and Honduras [12-15], and a case-control study that reported a congenital infection incidence of 3.3\% [16]. In Colombia, 12 cases were reported before 1986 [17] and there is a recent report on five cases of severe neonatal malaria caused by Plasmodium vivax, one of them with congenital infection based on epidemiological criteria [18].
C Biomed Central

๑ 2011 Piñeros-Jiménez et al; licensee BioMed Central Ltd. This is an Open Access article distributed under the terms of the Creative Commons Attribution License (http://creativecommons.org/licenses/by/2.0), which permits unrestricted use, distribution, and reproduction in any medium, provided the original work is properly cited. 
Because no studies have been carried out to establish the magnitude of CM in malaria endemic regions in Colombia, this study was designed to evaluate the prevalence of $\mathrm{CM}$ in a high-endemic region in Colombia and to describe its clinical and epidemiological characteristics.

\section{Methods}

\section{Study location}

This investigation was carried out in the Caribbean region of Urabá (Department of Antioquia, Colombia). This region is close to the Panama border, with tropical rainforest ecosystems and a population of 509,409 people, most of them African descendants (51.5\%) and under 25 years of age (59.0\%). Banana growing and cattle farming are the main economic activities in this region [19]. The study was conducted in the municipalities of Apartadó

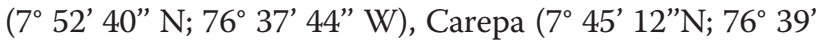
$\left.21^{\prime \prime} \mathrm{W}\right)$, Turbo ( $\left.8^{\circ} 05^{\prime} 42^{\prime \prime} \mathrm{N} ; 76^{\circ} 44^{\prime} 23^{\prime \prime} \mathrm{W}\right)$ and Necoclí $\left(8^{\circ} 25^{\prime} 39^{\prime \prime} \mathrm{N} ; 76^{\circ} 46^{\prime} 58^{\prime \prime} \mathrm{W}\right)$. The annual incidence of malaria in the region was higher than 40 cases per 1,000 inhabitants during 1998-2007, with unstable transmission, and where more than $75 \%$ of reported cases were caused by $P$. vivax [20]. An incidence of 4.1 cases of gestational malaria for each 1,000 live births has also been reported in this region [21].

\section{Study design and study population}

This was a prospective, descriptive study that was part of a larger epidemiological study on gestational malaria that included 2,117 pregnant women and was carried out from 2005-2007 by the Malaria Group of the Universidad de Antioquia in Colombia. Pregnant women were screened for Plasmodium spp. infection by thick smear at each prenatal visit and during delivery, and/or when they consulted due to a febrile syndrome. At birth, newborns from mothers who had a diagnosis of malaria in pregnancy (MIP) were clinically assessed and thick smears from peripheral blood and umbilical cord were analysed for the presence of the parasite. Weekly clinical and parasitological follow-up was carried out for 21 days in newborns, according to the criteria proposed by Henrys for CM in unstable transmission areas [22], such as this Latin-American region. The units of analysis were the newborns or the umbilical cords of mothers who had suffered MIP.

\section{Sample size}

The appropriate sample size was calculated [23] based on an annual average of 11,000 births [24], with a $10 \%$ estimated frequency of MIP ( $n=1,650$ newborns from mothers with MIP), and a $7 \%$ expected frequency of CM. The calculated sample size was 95 units of analysis, and we added $20 \%$ more to make up for possible losses during the follow-up period. A total of 116 newborns were finally selected according to the following inclusion criteria: 1) child of a pregnant woman who had been diagnosed with Plasmodium infection during prenatal control and/or during delivery, 2) newborn residing in the municipalities where the study was carried out, and 3) informed consent from the mother or guardian for the newborn's participation in the study.

\section{Definitions}

Congenital malaria: 1) newborn of a MIP mother with an infection caused by the same Plasmodium species at birth or during the 21-days follow-up period or 2) Plasmodium spp. infection of the umbilical cord [18].

Adolescent: under 20 years of age [25].

Low birth weight (LBW): less than 2,500 g [26].

Preterm birth (PB): birth before 37 weeks of gestation [26].

Small for gestational age: below the $10^{\text {th }}$ percentile of weight for gestational age, according to Lubchenco curves [26].

Gestational age: determined by ultrasound or the first day of the mother's last menstrual period.

\section{Thick smears}

\section{Peripheral blood thick smear}

capillary puncture was performed and the first drop of blood was discarded; the following drops were used for diagnosis [27]. Thick smears were stained with Field stain and read under a light microscope at $100 \times$ magnification. Parasitaemia was estimated against 200 leukocytes $(8,000$ leukocytes $/ \mu \mathrm{L}$, standard value) and was expressed as parasites $/ \mu \mathrm{L}$. P. falciparum parasitaemia was calculated counting ring forms, while $P$. vivax parasitaemia was calculated counting all asexual forms. A sample was considered negative if after the examination of 200 microscopic fields, no parasites were observed or when only $P$. falciparum gametocytes were observed [28].

\section{Umbilical cord thick smear}

$1 \mathrm{~mL}$ of blood was extracted from the umbilical vein during delivery [23]. Two thick smears were made and analysed using the same technique previously described [28].

\section{Placental blood thick smear}

placentas were cleaned with $50 \mathrm{~mL}$ of $0.9 \%$ saline solution. A $1-\mathrm{cm}^{3}$ incision was made in a cotyledon close to the umbilical cord, from where placental blood samples were collected [29].

\section{Data collection}

Newborn data from birth, physical exam and anthropometric measurements were registered in a standardized form (Latin-American Centre for Perinatology) [30]. Registered variables were gender, birth weight, height, cephalic perimeter, and the APGAR score at one and 
five minutes after birth. Newborn health status was evaluated by a physician on a weekly basis, and thick blood smears were made from peripheral blood.

\section{Statistical analysis}

Statistical analyses were made with EpiInfo software, version 6.04 (Center for Disease Control and Prevention, USA; World Health Organization, Geneva, Switzerland). A descriptive analysis was made to summarise and present the information. Median and interquartile range (IQR) or mean and confidence interval were calculated for continuous variables (according to normal distribution of data), and absolute frequency and percentages were used for categorical variables. Mann Whitney's test and chi-squared test were used to compare maternal and neonatal characteristics between the newborn groups with and without CM. A significance level of $5 \%$ was chosen.

\section{Ethical considerations}

The project was approved by the Ethics Committee of the Faculty of Medicine, Universidad de Antioquia. The Colombian Ministry of Health research standards (resolution 008430/1993), the WHO ethical standards for research on human beings and the 2002 Helsinki declaration were taken into account. Informed consent was obtained from all the mothers of the newborns or from their legal guardians.

\section{Results}

\section{Findings in the mothers and newborns}

From a total of 220 pregnant women who were diagnosed with MIP during prenatal control, only 157 gave birth in a health facility and were accessible; 116 of them were selected to be included in the study after fulfilling the criteria. The general characteristics of the mothers and newborns included $(n=116)$ and not included $(n=41)$ in the study are shown in Table 1 . The only statistically significant difference between the mothers included and not included in the study was found in the median of years of residence in endemic areas $(p=0.024)$, the other characteristics were similar.

$37.9 \%$ of the mothers included in the study were adolescents and $6.4 \%$ were over 35 years of age; $21.8 \%$ were primigravida, $19.5 \%$ reported 3 or more previous pregnancies, and $69.8 \%$ had been living in malaria risk areas for 10 years or longer. $91.4 \%$ of the pregnant women were attending a prenatal care program with a median of 4 visits, $34.5 \%$ reported having at least one episode of malaria in the previous year, and $12.7 \%$ had PB; $9.1 \%$ of the newborns had LBW and $18.2 \%$ were small for gestational age.

One hundred and sixty-eight episodes of malaria (138 caused by $P$. vivax and 30 by $P$. falciparum) were diagnosed among the 116 mothers (average, 1.4 episodes per mother). The median for the gestational age at the time of diagnosis of the first malaria episode was 30.1 weeks (IQR: 22.2-35.8). Twenty-seven episodes of malaria were diagnosed in the mothers during delivery, 21 caused by $P$. vivax and six by $P$. falciparum; the median parasitaemia was 2,400 parasites/ $\mu \mathrm{L}$ (IQR: 400-5,560).

\section{Findings in the placenta}

Ninety-four placental blood samples were obtained from the 116 mothers; 17 (18\%) had Plasmodium infection (14 $P$. vivax and three $P$. falciparum) with a median parasitaemia of 200 parasites/ $\mu \mathrm{L}$ (IQR: 80-920). Two mothers who were reported as negative for Plasmodium infection in peripheral blood samples during the prenatal control and delivery, had parasites in the placentas (one $P$. vivax and one P. falciparum).

\section{Congenital malaria prevalence}

Of the 80 blood samples collected from the umbilical cords at birth, two (2.5\%) were positive for P. vivax. The 116 newborns were followed-up for $20.5 \pm 1.1$ days with an average of $2.8 \pm 1$ postnatal controls per neonate. During follow-up, three (2.6\%) neonates were diagnosed with Plasmodium spp. infection; two by $P$. vivax (one at birth and one on day 14), and one by $P$. falciparum (on day 8). CM was diagnosed in five cases, for a prevalence of $4.3 \%$, three diagnosed in the 116 newborns and two in the 80 umbilical cords. None of these results were positive in both units of analysis simultaneously.

\section{Characteristics of mothers and newborns with and without CM}

There were no significant differences in the characteristics of mothers of newborns with and without CM ( $\mathrm{p}>0.05)$ (Table 2). The median age of mothers with newborns with CM was 23 years (IQR: 21.5-31), had a median of 1.0 for previous pregnancies (IQR: 1.0-3.5), and had attended at least four prenatal controls. The median episodes of malaria during the current pregnancy was 1.0 (IQR: 1.0$1.5)$, and the median gestational age at the time of maternal malaria diagnosis was 30 weeks (IQR: 25.6-39.4). The median gestational age of the mothers of CM cases was 37.7 weeks (IQR: 37.3-40.3).

There were no significant differences in the anthropometric characteristics and neonatal adaptability among neonates with and without CM (Table 2). Medians of weight, length and cephalic perimeter at birth of CM cases were 3,000 g (IQR: 2800-3400), $48 \mathrm{~cm}$ (IQR: 44-49.5) and $34 \mathrm{~cm}$ (IQR: $31.5-34)$, respectively; all these measurements were above the $10^{\text {th }}$ percentile according to the Lubchenco curves.

The mother of the congenital case caused by P. falciparum presented clinical and laboratory signs compatible with severe malaria (parasite count of 106,640 ring forms/ 
Table 1 General characteristics of the mothers and newborns included and not included in the study

\begin{tabular}{|c|c|c|c|c|c|}
\hline \multirow[t]{2}{*}{ Variable } & \multicolumn{2}{|c|}{ Cases included in the study } & \multicolumn{2}{|c|}{ Cases not included in the study } & \multirow{2}{*}{$\begin{array}{c}\text { Mann-Whitney } \\
\text { p value }\end{array}$} \\
\hline & $\mathrm{n}$ & $\begin{array}{c}\text { Q2 } \\
\text { (Q1 - Q3) }\end{array}$ & $\mathrm{n}$ & $\begin{array}{c}\mathrm{Q} 2 \\
(\mathrm{Q} \text { - Q3) }\end{array}$ & \\
\hline Maternal age & 115 & $\begin{array}{c}21 \\
(18-27)\end{array}$ & 40 & $\begin{array}{c}22 \\
(18-28)\end{array}$ & 0,845 \\
\hline Maternal haemoglobin after week 20 (g/dL) & 80 & $\begin{array}{c}11.5 \\
(10.1-2.0)\end{array}$ & 21 & $\begin{array}{c}11.6 \\
(10.7-11.6)\end{array}$ & 0,855 \\
\hline Years of residence in malaria area & 114 & $\begin{array}{c}18 \\
(10-23)\end{array}$ & 41 & $\begin{array}{c}15 \\
(5-20)\end{array}$ & 0,024 \\
\hline Previous pregnancies & 116 & $\begin{array}{c}2 \\
(1-3)\end{array}$ & 41 & $\begin{array}{c}1 \\
(1-3)\end{array}$ & 0.91 \\
\hline Episodes of malaria in the previous year & 78 & $\begin{array}{c}0 \\
(0-1)\end{array}$ & 33 & $\begin{array}{c}0 \\
(0-1)\end{array}$ & 0,347 \\
\hline Gestational age at birth & 109 & $\begin{array}{c}38.4 \\
(37.8-39.7)\end{array}$ & 38 & $\begin{array}{c}39 \\
(37.7-40)\end{array}$ & 0,055 \\
\hline Neonatal weight & 115 & $\begin{array}{c}2875 \\
(2500-3425)\end{array}$ & 39 & $\begin{array}{c}3005 \\
(2800-3400)\end{array}$ & 0,280 \\
\hline Neonatal length & 116 & $\begin{array}{c}48 \\
(47-50)\end{array}$ & 40 & $\begin{array}{c}49 \\
(47-50)\end{array}$ & 0,697 \\
\hline APGAR at 1 minute & 112 & $\begin{array}{c}8 \\
(7-9)\end{array}$ & 40 & $\begin{array}{c}8 \\
(8-9)\end{array}$ & 0,616 \\
\hline Episodes of malaria during current pregnancy & 116 & $\begin{array}{c}1 \\
(1-1)\end{array}$ & 41 & $\begin{array}{c}1 \\
(1-2)\end{array}$ & 0,166 \\
\hline
\end{tabular}

Q2: median Q1-Q3: quartil 1-quartil 3.

$\mu \mathrm{L}$ and spontaneous bleeding at venopuncture sites), and required hospitalization in a high complexity health institution in the immediate postpartum period. The mothers of the other CM cases, caused by P. vivax, were classified as having acute non-complicated malaria; three were diagnosed at the time of delivery and had concomitant placental infection, and one was diagnosed in the third trimester of pregnancy during the prenatal control (Table 3). All mothers and infected newborns received anti-malarial treatment according to the national protocols [31].

Newborns with $P$. vivax infection in the umbilical cord (Table 3, case 1 and case 4) did not show infection in peripheral blood during follow-up or manifested clinical signs of active infection or severe disease; thus, no anti-

Table 2 Maternal and neonatal characteristics of congenital and non-congenital malaria groups

\begin{tabular}{lcc}
\hline Variables & $\begin{array}{c}\text { Congenital malaria }(\mathbf{n}= \\
\mathbf{5})\end{array}$ & $\begin{array}{c}\text { Non congenital malaria }(\mathbf{n}= \\
\mathbf{1 1 1})\end{array}$ \\
\hline value
\end{tabular}

*Fisher's exact test, Q1-Q3: quartil 1-quartil 3. 
Table 3 Malaria and thick smear findings in CM cases

\begin{tabular}{|c|c|c|c|c|c|}
\hline & Case 1 & Case 2 & Case 3 & Case 4 & Case 5 \\
\hline \multicolumn{6}{|l|}{ Malaria findings } \\
\hline Episodes of maternal malaria & $1 P_{V}$ & $\begin{array}{l}1 P V \\
1 P f\end{array}$ & $1 P_{V}$ & $1 P v$ & $1 P f$ \\
\hline $\begin{array}{l}\text { Gestational age at malaria diagnosis (weeks + } \\
\text { days) }\end{array}$ & $37+2$ & $\begin{array}{l}\text { Pf: } 24+2 \\
\text { Pv: } 40+2\end{array}$ & $27+6$ & $40+4$ & 30 \\
\hline Type of malaria syndrome in mothers & $\begin{array}{c}\text { acute } \\
\text { uncomplicated } \\
\text { malaria }\end{array}$ & $\begin{array}{c}\text { acute } \\
\text { uncomplicated } \\
\text { malaria }\end{array}$ & $\begin{array}{c}\text { acute } \\
\text { uncomplicated } \\
\text { malaria }\end{array}$ & $\begin{array}{c}\text { acute } \\
\text { uncomplicated } \\
\text { malaria }\end{array}$ & $\begin{array}{l}\text { severe } \\
\text { malaria }\end{array}$ \\
\hline $\begin{array}{l}\text { Clinical status of neonates at the time of } \\
\text { congenital malaria diagnosis }\end{array}$ & afebrile & afebril & afecrile & afebrile & severely ill \\
\hline \multicolumn{6}{|l|}{ Thick smear findings } \\
\hline Maternal blood during delivery & $P V($ nd) & PV (560) & Neg. & PV (120) & $\begin{array}{c}P f \\
(106640)\end{array}$ \\
\hline Placental blood & PV (920) & PV (440) & Neg. & $P \vee(80)$ & Neg. \\
\hline Umbilical cord blood & PV 1860) & Neg. & Neg. & $P \vee(80)$ & Neg. \\
\hline Neonatal blood & Neg. & Pv (40) day 1 & PV (160) day 14 & Neg. & $\begin{array}{l}\text { Pf }(120) \\
\text { day } 8\end{array}$ \\
\hline
\end{tabular}

Pv: Plasmodium vivax, Pf: Plasmodium falciparum

( ) parasite/ $\mu \mathrm{L}$.

malarial treatment was administered. The P. falciparum $\mathrm{CM}$ case was severely ill since birth due to prematurity and to hyaline membrane disease (Table 3, case 5). During hospitalization in a neonatal intensive care unit, the newborn was diagnosed with early neonatal sepsis by Escherichia coli. The thick smear was negative at birth, but serial thick smears started on day 6 revealed P. falciparum infection on day $8(120$ rings $/ \mu \mathrm{L})$.

\section{Discussion}

$\mathrm{CM}$ is one of the least known and studied adverse events of MIP [2]. The present study is the first epidemiological report about CM in Colombia and could be considered as being one of the first for regions where $P$. vivax malaria is the most frequent specie. This study found a prevalence of $\mathrm{CM}$ of $4.3 \%$ among newborns from mothers with MIP in the Urabá region. Such frequency was similar to that found in Nigeria by Falade et al, who identified a 5.1\% parasitaemia in samples from newborns whose mothers had suffered from MIP [11], and to the prevalence of 3.3\% (1/30) found by Fernández et al in Honduras in 2001 [16], but greater than that reported by Alves et al in Brazil, who found just one case of $\mathrm{CM}$ in 2,781 cases of malaria between 1980 and 1994 in the Campinas region [15]. 80\% (four out of five) of CM cases in this study were caused by P. vivax, the Plasmodium responsible for most of the malaria cases in the Americas [32].

The umbilical cord and newborns were the units of analysis for obtaining such prevalence, and the first 21 days of life were defined as the time limit for obtaining samples. Although in P. falciparum hyper-endemic regions the first seven days of life are the limit to define an infection as congenital, we chose a time limit that has been proposed for areas of low endemicity and unstable transmission, which is an accepted limit for infections caused by non P. falciparum species [22]. One of cases was identified at postnatal day14, within the time limit, however it is not possible to guarantee that it was not caused by vector transmission of the parasite because we had no information on the control measures used to protect this neonate against malaria; the question remains on whether it was a postnatal infection, however if we consider the unstable and low malaria transmission rates of the study location, is not likely that this occurred. The CM case by $P$. falciparum was diagnosed at postnatal day 8 , however this newborn was referred after birth to the Neonatal Care Unit located in a non-endemic area, so we consider it was indeed a case of CM.

Positive umbilical cords and neonatal peripheral blood samples from units of analysis were included for calculating the prevalence, and all complete or partial units formed the denominator. It became evident in this study that obtaining samples from these two sites was essential for diagnosing CM and determining the magnitude of this disease. If the units of analysis were divided according to sample site, a prevalence of $2.5 \%(2 / 80)$ and of $2.6 \%(3 / 116)$ would have been obtained for malaria positive samples from the umbilical cord and neonatal peripheral blood, respectively.

The prevalence of CM reported here was obtained using thick smear as the diagnostic test; however, a greater prevalence might have been found if more sensitive techniques, such as PCR, had been used. Kamwendo et al and, recently, Mwangoka et al have found in P. falciparum endemic regions that when using thick smears to diagnose 
malaria from umbilical cord samples, the frequencies range from $0.4 \%$ to $6.0 \%$, and when PCR is used the frequencies increase to $20 \%$ to $61 \%$ for samples taken from the same site $[33,34]$.

Low parity, fever during the last trimester of gestation, maternal malaria at birth, placental infection by Plasmodium spp. and low socioeconomic level have all been associated with greater CM frequency $[11,35,36]$. Age of pregnant mother and maternal infection by HIV have been associated with greater Plasmodium trans-placental transmission risk, with a higher infection frequency and placental damage [37-40]. Falade et al in 2002, highlighted the strong relationship between maternal parasitaemia at birth and positive placental samples with congenital infection [11].

The study identified four cases of $\mathrm{CM}$, three by $P$. vivax and one by $P$. falciparum, where the mothers had malaria during delivery; placental infection was also found in the three CM cases by $P$. vivax. The other mother had P. vivax malaria 10 weeks before giving birth. A previous report by our group on neonatal malaria (where vertical $P$. vivax transmission was suspected), showed that two of the four positive mothers were in their first or second gestation [18]; the present study found that three (60\%) of the five mothers of the CM cases were secundiparous. In contrast to other reports $[18,41]$, the mothers of the $\mathrm{CM}$ cases in the present study were older than 20 years of age.

LBW has been associated with infection by $P$. falciparum during pregnancy and at birth, which is explained by a combination of intrauterine growth restriction and $\mathrm{PB}$ [42] in both high and low malaria transmission regions, accompanied by almost a four-fold increased risk when there has been placental infection [41]. In this study, only the newborn infected by $P$. falciparum weighed less than 2,500 grams and was born at week 30 of gestation. Such $\mathrm{PB}$ could have been due to the mother presenting P. falciparum infection at birth. Infection by this species has been associated with a greater risk of PB due to the magnitude of the induced inflammatory response. Many reports have associated LBW with MIP caused by P. falciparum [41], but only a few have shown the effect of the infection by $P$. vivax on birth weight. Nosten et al reported an increased risk of LBW associated with $P$. vivax infection [43]. The absence of LBW in CM cases of mothers with MIP by this specie was notable in this report; this could be explained because the infection occurred at the end of the gestation and the gestations went to full term. Anthropometric measurements in all newborns, including the premature case, were appropriate for the gestational age.

In low endemic and unstable transmission areas the acquisition of immunity against Plasmodium spp. is difficult and incomplete, so there is little passage of antibodies through the placenta [41]. In this scenario, the clinical manifestations of a CM case are usually fever accompanied by irritability, anorexia, hepatosplenomegaly, haemolytic anaemia and ichtericia $[14,18,44]$. In contrast, in high endemic and stable transmission regions where it is considered that the opposite is true, signs and symptoms of active infection are infrequent $[45,46]$.

This study location had unstable transmission of malaria, which has thus hampered the induction of effective immunity against the parasite. In contrast to a previous report on cases of neonatal malaria by $P$. vivax in the same region, in which the newborns presented severe disease [18], in the present study the CM cases by this specie were asymptomatic. This difference could have been due to the infections being identified during the pre-clinical phase as a consequence of active search, and to a timely treatment.

The newborn with CM by $P$. falciparum presented a very serious disease requiring treatment in a neonatal intensive care unit outside the endemic zone. Other conditions including sepsis by Escherichia coli, hyaline membrane disease and PB converged in this patient and can explain the extreme severity of the clinical picture. Research in severe malaria has shown that some cases of extreme clinical severity in both children and adults can be explained by co-infection with bacterial agents [47] which, even in the case of Gram negative bacteraemia, have been reported as increasing the risk of death from malaria $[48,49]$.

\section{Conclusions}

1) $\mathrm{CM}$ is a frequent event in newborns of mothers who have had malaria during pregnancy in a coastal region of Colombia;

2) The main maternal characteristics in these cases of $\mathrm{CM}$ were having malaria during the last trimester or during delivery, and placental infection.

\section{Acknowledgements}

The authors would like to thank the personnel from the local hospitals, the ETV control programmes and the secretariats of health of the municipalities participating in the study. Also, the field personnel from the Malaria Group at the Universidad de Antioquia, the personnel from the Antonio Roldán Betancur Institute of Tropical Medicine at the Instituto de Ciencias de la Salud (ICMT-CES), doctor Armando Galeano from the Antioquia District Health Department and doctor Jaime Carmona-Fonseca for their support for the study, and to the mothers and newborn babies who participated in this study.

Financing

This study was financed by the Colombian Science, Technology and Innovation Department (COLCIENCIAS) within the framework of the Gestational and Congenital Malaria in Urabá project (1115-04-17041), the Antioquia District Health Department and the Universidad de Antioquia.

\section{Author details}

'Malaria Group, Universidad de Antioquia, Calle 62, \# 52-59, Laboratorio 610, Medellín, Colombia. ${ }^{2}$ Doctorado Interfacultades en Salud Pública, Universidad Nacional de Colombia, Bogotá, Colombia. ${ }^{3}$ nnstituto de Medicina Tropical Antonio Roldán Betancur-CES, Apartadó, Colombia. 


\section{Authors' contributions}

JGPJ: conceiving and designing the research proposal, analysing the data and writing the manuscript; GA: analysing the data and writing the manuscript; AT: designing the investigation, coordinating the field research and critically reviewing the manuscript; MA: designing the research, acquiring the data and critically reading the manuscript; SC: acquiring the data and critically reading the manuscript; SB: conceiving and designing the research proposal, interpreting the data and writing the manuscript. All authors read and approved the final manuscript.

\section{Competing interests}

The authors declare that they have no competing interests.

Received: 8 October 2010 Accepted: 16 August 2011 Published: 16 August 2011

\section{References}

1. Fondo de las Naciones Unidas para la Infancia-UNICEF: Estado Mundial de la Infancia 2009. 2010 [http://www.unicef.org/spanish/sowc09/report/ report.php]

2. Menendez C, Mayor A: Congenital malaria: the least known consequence of malaria in pregnancy. Semin Fetal Neonatal Med 2007, 12:207-213.

3. Covell G: Congenital malaria. Trop Dis Bull 1950, 47:1147-1167.

4. Bruce-Chwatt LJ: Malaria in African infants and children in southern Nigeria. Ann Trop Med Parasitol 1952, 46:173-200.

5. Piñeros J, Blair S: Malaria y gestación. Infectio 2002, 6:168-176.

6. Uneke CJ: Congenital Plasmodium falciparum malaria in sub-Saharan Africa: a rarity or frequent occurrence? Parasitol Res 2007, 101:835-842.

7. Lehner PJ, Andrews CJ: Congenital malaria in Papua New Guinea. Trans $R$ Soc Trop Med Hyg 1988, 82:822-826.

8. Larkin GL, Thuma PE: Congenital malaria in a hyperendemic area. Am J Trop Med Hyg 1991, 45:587-592.

9. Obiajunwa PO, Owa JA, Adeodu OO: Prevalence of congenital malaria in Ile-Ife, Nigeria. J Trop Pediatr 2005, 51:219-222.

10. Mukhtar MY, Lesi FE, Iroha EU, Egri-Okwaji MT, Mafe AG: Congenital malaria among inborn babies at a tertiary centre in Lagos, Nigeria. $J$ Trop Pediatr 2006, 52:19-23.

11. Falade C, Mokuolu O, Okafor H, Orogade A, Falade A, Adedoyin O, Oguonu T, Aisha M, Hamer DH, Callahan MV: Epidemiology of congenital malaria in Nigeria: a multi-centre study. Trop Med Int Health 2007, 12:1279-1287.

12. Fernandez-Torrano M: [Congenital malaria. Presentation of 3 cases]. Bol Med Hosp Infant Mex 1988, 45:36-41.

13. Diaz R, Funes J, Becerra J, Pineda C, Méndez N: Malaria congenital: report de un caso y revisión de literatura. Rev Med Hondur 1995, 63:117-119.

14. Marques HH, Vallada MG, Sakane PT, Boulos M: [Congenital malaria. Case reports and a brief review of literature]. J Pediatr (Rio J) 1996, 72:103-105.

15. Alves MJ, Rangel O, De Souza SS: [Malaria in the region of Campinas, Sao Paulo, Brazil, 1980 to 1994]. Rev Soc Bras Med Trop 2000, 33:53-60.

16. Fernández R, García Y, Alger J: Malaria y gestación: observaciones clínicoepidemiológicas en dos zonas geográficas de Honduras. Rev Med Hondur 2001, 69:8-18

17. Piñeros J: Congenital Malaria. In Tópicos selectos de infectología. Edited by: Carmona-Fonseca J. Medellín: Universidad de Antioquia; 2002:

18. Pineros-Jimenez JG, Arboleda M, Jaramillo JC, Blair S: [Report of five cases of severe neonatal Plasmodium vivax malaria in Urabá, Colombia]. Biomedica 2008, 28:471-479.

19. Departamento Administrativo Nacional de Estadística-DANE: Censo General de Colombia 2005. 2010 [http://www.dane.gov.co/censo/files/ libroCenso2005nacional.pdf].

20. Dirección Seccional de Salud de Antioquia: Enfermedades transmitidas por vectores 2000-2010 por municipio. 2010 [http://www.dssa.gov.co/ index.php/estadisticas/eventos-de-salud-publica].

21. Arismendi-Solano M: Magnitud de la malaria gestacional en el Urabá Antioqueño 2000-2005. 2010 [http://tesis.udea.edu.co/dspace/bitstream/ 10495/432/1/MagnitudMalariaGestacionalUraba.pdf].

22. Henrys D: A propósito de un caso de paludismo congénito en Thomonde, Haití. Acta Médica Dominicana 1983, 6:216-8.

23. Lwanga S, Lameshow S: Determinación del tamaño muestral en los estudios sanitarios. Manual práctico Geneva: World Health Organization; 2001.
24. Gobernación de Antioquia: Anuario Estadístico de Antioquia 2007. 2008 [http://www.antioquia.gov.co/antioquia-v1/organismos/planeacion/anuario2007/index.htm].

25. World Health Organization: Growing in confidence: programming for adolescent health and development: lessons from eight countries Geneva: WHO press; 2002.

26. World Health Organization: Managing complications in pregnancy and childbirth: a guide for midwives and doctor Geneva: WHO press; 2000.

27. Tobian AA, Mehlotra RK, Malhotra I, Wamachi A, Mungai P, Koech D, Ouma J, Zimmerman P, King CL: Frequent umbilical cord-blood and maternal-blood infections with Plasmodium falciparum, P. malariae and P. ovale in Kenya. J Infect Dis 2000, 182:558-563.

28. Lopez-Antuñano F, Schmunis G: Diagnóstico de malaria. Washington: Organización Panamericana de la Salud; 1988.

29. Kassberger F, Birkenmaier A, Khattab A, Kremsner PG, Klinkert MQ: PCR typing of Plasmodium falciparum in matched peripheral, placental and umbilical cord blood. Parasitol Res 2002, 88:1073-1079.

30. CLAP/SMR-OPS/OMS: Historia clínica perinatal: instrucciones de llenado y definición de terminos. 2005 [http://www.clap.ops-oms.org/web_2005/ BOLETINES\%20Y\%20NOVEDADES/EDICIONES\%20DEL\%20CLAP/CLAP\% 201563.pdf].

31. República de Colombia, Ministerio de Salud, Dirección General de Promoción y Prevención: Guía de atención de malaria. 2000, Norma técnica 31/03/2000, República de Colombia, Diario Oficial 43.956, Bogotá.

32. World Health Organization: World Malaria Report 20082009 [http://apps. who.int/malaria/wmr2008/malaria2008.pdf].

33. Kamwendo DD, Dzinjalamala FK, Snounou G, Kanjala MC, Mhango CG, Molyneux ME, Rogerson SJ: Plasmodium falciparum: PCR detection and genotyping of isolates from peripheral, placental, and cord blood of pregnant Malawian women and their infants. Trans $R$ Soc Trop Med Hyg 2002, 96:145-149.

34. Mwangoka GW, Kimera SI, Mboera LE: Congenital Plasmodium falciparum infection in neonates in Muheza district, Tanzania. Malar J 2008, 7:117.

35. Okafor UH, Oguonu T, Onah HE: Risk factors associated with congenital malaria in Enugu, south eastern Nigeria. J Obstet Gynaecol 2006, 26:612-616.

36. Runsewe-Abiodun IT, Ogunfowora OB, Fetuga BM: Neonatal malaria in Nigeria-a 2 year review. BMC Pediatr 2006, 6:19

37. Perrault SD, Hajek J, Zhong K, Owino SO, Sichangi M, Smith G, Shi YP, Moore JM, Kain KC: Human immunodeficiency virus co-infection increases placental parasite density and trans-placental malaria transmission in western Kenya. Am J Trop Med Hyg 2009, 80:119-125.

38. Steketee RW, Wirima JJ, Slutsker L, Roberts JM, Khoromana CO, Heymann DL, Breman JG: Malaria parasite infection during pregnancy and at delivery in mother, placenta, and newborn: efficacy of chloroquine and mefloquine in rural Malawi. Am J Trop Med Hyg 1996, 55(1 suppl):24-32.

39. Ter kuile FO, Parise ME, Verhoeff FH, Udhayakumar V, Newman RD, Van Eijk AM, Rogerson SJ, Steketee RW: The burden of co-infection with human immunodeficiency virus type 1 and malaria in pregnant women in sub-Saharan Africa. Am J Trop Med Hyg 2004, 71(2 suppl):41-54.

40. Uneke CJ: Impact of placental Plasmodium falciparum malaria on pregnancy and perinatal outcome in sub-Saharan Africa: ii: effects of placental malaria on perinatal outcome; malaria and HIV. Yale J Biol Med 2007, 80:95-103.

41. Desai M, Ter Kuile FO, Nosten F, Mcgready R, Asamoa K, Brabin B, Newman RD: Epidemiology and burden of malaria in pregnancy. Lancet Infect Dis 2007, 7:93-104.

42. Kalanda BF, Verhoeff FH, Chimsuku L, Harper G, Brabin BJ: Adverse birth outcomes in a malarious area. Epidemiol Infect 2006, 134:659-666.

43. Nosten F, Mcgready R, Simpson JA, Thwai KL, Balkan S, Cho T, Hkirijaroen L, Looareesuwan S, White NJ: Effects of Plasmodium vivax malaria in pregnancy. Lancet 1999, 354:546-549.

44. Lesko CR, Arguin PM, Newman RD: Congenital malaria in the United States: a review of cases from 1966 to 2005. Arch Pediatr Adolesc Med 2007, 161:1062-1067.

45. Valecha N, Bhatia S, Mehta S, Biswas S, Dash AP: Congenital malaria with atypical presentation: a case report from low transmission area in India. Malar J 2007, 6:43

46. Wiwanitkit V: Congenital malaria in Thailand, an appraisal of previous cases. Pediatr Int 2006, 48:562-565. 
47. Gwer S, Newton CR, Berkley JA: Over-diagnosis and co-morbidity of severe malaria in African children: a guide for clinicians. Am J Trop Med Hyg 2007, 77(6 suppl):6-13.

48. Bruneel F, Hocqueloux L, Alberti C, Wolff M, Chevret S, Bedos JP, Durand R, LE Bras J, Regnier B, Vachon F: The clinical spectrum of severe imported falciparum malaria in the intensive care unit: report of 188 cases in adults. Am J Respir Crit Care Med 2003, 167:684-689.

49. Fenn B, Morris SS, Black RE: Comorbidity in childhood in northern Ghana: magnitude, associated factors, and impact on mortality. Int J Epidemiol 2005, 34:368-375.

doi:10.1186/1475-2875-10-239

Cite this article as: Piñeros-Jiménez et al.: Congenital malaria in Urabá, Colombia. Malaria Journal 2011 10:239.

\section{Submit your next manuscript to BioMed Central} and take full advantage of:

- Convenient online submission

- Thorough peer review

- No space constraints or color figure charges

- Immediate publication on acceptance

- Inclusion in PubMed, CAS, Scopus and Google Scholar

- Research which is freely available for redistribution

Submit your manuscript at www.biomedcentral.com/submit
() Biomed Central 